\title{
Mixture of tree species enhances stability of soil bacterial community through phylogenetic diversity
}

\author{
Xiao Zhang ${ }^{\mathrm{a}, \mathrm{b}}$, Yongtao Huang ${ }^{\mathrm{a}}$, Shirong Liu ${ }^{\mathrm{b}}$, Shenglei Fu ${ }^{\mathrm{a}}$, Angang Ming ${ }^{\mathrm{c}, \mathrm{d}}$, \\ Xiangzhen $\mathrm{Li}^{\mathrm{e}}$, Minjie $\mathrm{Yao}^{\mathrm{e}},{\mathrm{Huan} \mathrm{Li}^{\mathrm{f}} \text {, Chao Tian }}^{\mathrm{g}}$
}

Correspondence: Shirong Liu. E-mail: $\underline{\text { liusr@ caf.ac.cn }}$

${ }^{\mathrm{a} C o l l e g e}$ of Environment and Planning, Henan University, Jinming Avenue, Kaifeng,

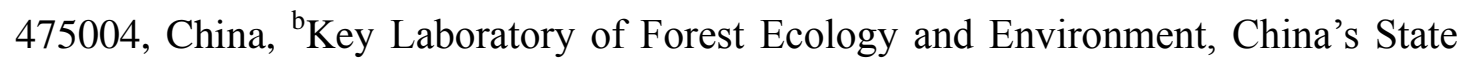
Forestry Administration, Institute of Forest Ecology, Environment and Protection, Chinese Academy of Forestry, No. 2 Dongxiaofu, Haidian District, Beijing 100091, China, E-mail: liusr9311@ 163.com, ${ }^{c}$ Experimental Center of Tropical Forestry, CAF, Pingxiang 532600, 'Guangxi Youyiguan Forest Ecosystem Research Station, Pingxiang 532600, China, ${ }^{\mathrm{e}}$ Key Laboratory of Environmental and Applied Microbiology, Chinese Academy of Sciences and Environmental Microbiology; Key Laboratory of Sichuan Province, Chengdu Institute of Biology, Chinese Academy of Sciences, Chengdu 610041, China, ${ }^{\mathrm{f}}$ Institute of Occupational Health and Environmental Health, School of Public Health, Lanzhou University, Lanzhou 730000, China and ${ }^{\mathrm{g}}$ Department of Earth Sciences, Indiana University-Purdue University, Indianapolis (IUPUI), Indianapolis, Indiana 46202, USA

Running Title: Phylogenetic diversity and stability relation

This is the author's manuscript of the article published in final edited form as:

Zhang, X., Huang, Y., Liu, S., Fu, S., Ming, A., Li, X., ... Tian, C. (2019). Mixture of tree species enhances stability of soil bacterial community through phylogenetic diversity. European Journal of Soil Science, 0(ja). https://doi.org/10.1111/ejss. 12780 


\section{Summary}

The composition of tree species might influence microbial diversity considerably, yet investigation of the consequences of changes in diversity on stability of the microbial community is still in its early stages. Understanding how diversity governs community stability is vital for predicting the response of an ecosystem to environmental changes. Phylogenetic diversity (PD) describes the distinct evolution of species in a community, and might be useful for estimating the effects of biodiversity on ecosystem function and stability. High-throughput 16S rRNA gene sequencing was used to examine soil bacterial phylogenetic distances, phylogenetic diversity and interactions between individuals in five single-species plantations and three mixed-species plantations. The plantations were established on the same initial substrate, and sampling was at 68 relatively spatially independent sites. Our results showed that mixed tree species enhanced soil bacterial phylogenetic diversity and community stability, and that phylogenetic diversity had a positive effect on stability of the soil microbial community. We also found evidence that microbial communities characterized by distantly related species with weak interactions were more stable in mixed plantations than communities with strong interactions in single-species plantations. These results may be explained by the 'insurance hypothesis', that large phylogenetic diversity of microbial communities which share different ecological niches insures them against decline in their stability. This is because, even if some microbial species fail to deal with environmental change, others might not necessarily be affected similarly. Our findings demonstrate that phylogenetic diversity is the main controlling factor of the variation in stability across sites and requires more attention in sustainable forest management.

Keywords: Single-species plantations, Mixed-species plantations, Phylogenetic 
distance, Interaction, Diversity-stability relation

\section{Highlights}

- Mixed species considerably improved stability of soil bacterial community.

- Bacterial phylogenetic diversity was greater in mixed- than in single-species plantations.

- Mixed species resulted in weak microbial interactions in a community.

- There was a strong relation between phylogenetic diversity and stability.

\section{Introduction}

Community stability is an important goal in the conservation of biodiversity and the effective management of natural resources (Cardinale et al., 2012). The stability of ecosystems is controlled by the stability of populations and communities that contribute to ecosystem functions (McCann, 2000). However, attempts to quantify the relations between diversity and stability are not consistent. In theory, increases in diversity give rise to increases in ecosystem complexity and stability (Yachi \& Loreau, 1999). Several studies have shown positive diversity-stability relations among microbial communities (e.g. McCann, 2000; Roger et al., 2016). Conversely, Jiang (2007) suggested that microbial diversity is of little importance to ecosystem stability because most microbial taxa are functionally redundant. Wertz (2007) also supported this view by finding no soil microbial diversity-stability relations after artificially reducing microbial diversity. An explanation for the contradictory findings might be that species diversity is important only when these species occupy different niches or their functional contributions to the ecosystem differ (Cadotte et al., 2012).

Recent studies have suggested that promoting stability and productivity through

This article is protected by copyright. All rights reserved. 
biodiversity results from increased niche differentiation (Zuppinger-Dingley et al., 2014). Phylogenetic diversity describes the distinct evolution of species and phylogenetic distances in a community, which can be used as an alternative for measuring ecological niches (Webb et al., 2002; Cadotte et al., 2012). Communities with weak phylogenetic diversity usually have large niche overlap and are more likely compete for similar resources. In contrast, communities with large phylogenetic diversity are expected to have more niche differentiation and use complementary resources, and thus are more stable against fluctuations in the environment and resources (Cadotte et al., 2012). There are two possible explanations for why increasing phylogenetic diversity could bring about greater community stability in a microbial community. First, species in a microbial community with weak phylogenetic diversity (i.e. short phylogenetic distances between microbial individuals) share similar niches and thus have similar environmental sensitivity and ability to survive, resulting in weak stability because most species respond synchronously to environmental change (Yachi \& Loreau, 1999). In contrast, species in a microbial community with large phylogenetic diversity (i.e. long phylogenetic distances between microbial individuals) have different ecological niches (i.e. complementary environment and resource use). This maintains a highly stable microbial community because even if some species are unsuccessful in the face of environmental change, others might not be affected (referred to as the 'insurance hypothesis'; Yachi \& Loreau, 1999). Second, microbial communities with large phylogenetic diversity (i.e. species occupying distinct niches) could result in weak interactions among individuals because of the reduction in positive relations arising from co-aggregation (Cadotte et al., 2012). Increasing community stability is usually accompanied by decreases in average interactions. This is because strong interactions 
among species might result in the community shifting as a whole and then follow by amplification of the community response to environmental fluctuations (May, 1972; Yachi \& Loreau, 1999).

Previous studies on stability of the microbial community have mainly focused on the relation between diversity and stability, but have not accounted for the importance of interactions between different microbial species in a community (Faust \& Raes, 2012). Soil microbes can form networks through various types of interactions. Understanding the interactions between different species or populations within a given community is essential for estimating and predicting community stability (McCann, 2000). Network analysis can quantify microbial interactions (e.g. mutualism, competition and other complex ecological relations (Faust \& Raes, 2012), and can be used to study community stability and predict community behaviour in altered conditions.

To meet the ever-growing demand for forest products, to achieve carbon sequestration goals and avoid excessive harvesting of natural forests, planted forests are rapidly becoming a major component of worldwide afforestation and reforestation (Pan et al., 2011). Nevertheless, there are serious concerns regarding monospecific plantations, including the loss of biodiversity and potential declines in ecosystem stability (Sicardi et al., 2004). In contrast to single-species plantations, mixed-species plantations are likely to have greater productivity and stability (Kelty, 2006). For example, outbreaks of phytophagous insects are common in single-species plantations but are rare in diverse tropical forests, and even in mixed plantations (McCann, 2000). Given the myriad of interactions between above- and below-ground communities and their well-known effects on ecosystem function (Barberán et al., 2015), it is often assumed that the composition of belowground microbial communities and 
aboveground plant communities will reflect one another.

The functional traits of dominant trees species could influence the composition, activity and diversity of soil microbial communities through changes in microclimate of the soil-inhabiting microorganisms, production of litter and root exudates, and interactions with root symbiotic organisms such as mycorrhizal fungi (Prescott \& Grayston 2013). Recent studies have demonstrated there are strong relations between the soil microbial community and factors such as $\mathrm{pH}$, organic matter content, $\mathrm{N}$ content and the C:N ratio (Rousk, et al., 2010). Soil bacterial taxa inhabit soil niches at a very small scale, and thus are expected to have close connections with soil properties (Vos et al., 2013). Recent studies have suggested that dominant trees affect the composition, activity and diversity of the soil bacterial community, resulting possibly from changes in soil properties (Prescott \& Grayston, 2013). Although many studies have examined the effects of different plant types or a range of disturbances on soil microbial community composition, structure and functioning (Griffiths \& Philippot, 2013), few studies have focused on the changes to soil microbial community complexity and stability.

Our study evaluated the stability, phylogenetic diversity and interactions between different species of soil microbial communities in single- and mixed-species plantations at the Experimental Center of Tropical Forestry, in subtropical China. This site was chosen because it has served as a model to investigate the nature and ecosystem function of single- and mixed-species plantation for over a decade (Kang et al., 2005; Huang et al., 2014). We hypothesized that a more complex composition of tree species would improve stability of the soil microbial community through phylogenetic diversity and interactions between microbial species. We first tested whether mixed-species plantations had increased phylogenetic diversity and reduced 
interactions among microbial species compared with single-species plantations. Second, we evaluated whether mixed-species plantations had more stable microbial communities than single-species plantations. Lastly, we modelled the relations between microbial phylogenetic diversity and stability.

\section{Materials and methods}

\section{Study site description and experimental design}

This study was carried out at the Experimental Center of Tropical Forestry $\left(22^{\circ} 10^{\prime} \mathrm{N}\right.$, $\left.106^{\circ} 50^{\prime} \mathrm{E}\right)$, Chinese Academy of Forestry, in Pingxiang City, Guangxi Zhuang Autonomous Region, People's Republic of China. The average annual rainfall is 1400 mm, occurring primarily from April to September, and the average annual air temperature is $21^{\circ} \mathrm{C}$. The Experimental Center contains 16000 ha of artificial plantations, comprising 30 tree species, including single- and mixed-species plantations. The soil has formed by the weathering of granite and is classified as a red soil according to the Chinese soil classification system, which is equivalent to an Oxisol in the USDA Soil Taxonomy (Huang et al., 2014).

The climate is similar across the study area, as was the initial composition of the parent material, therefore, the composition of tree species has been the major factor influencing differences in soil development (plant and soil development processes at the study site, see Figure S1, Supporting Information). Historically, the study site had a typical subtropical evergreen forest before the establishment of a Cunninghamia lanceolata (lamb.) Hook. plantation in the 1950s. Single- and mixed-species tree plantations were established in 1983, following clear-cutting of the $C$. lanceolata plantation. In this study, five single-species plantations and three mixed-species plantations were selected based on their similarities in topography, soil texture, stand 
age and management history. The five single-species plantations included Pinus massoniana Lamb., Castanopsis hystrix Miq., Eucalyptus urophylla S.T. Blake, Erythrophleum fordii Oliv., and Gmelina arborea Roxb., whereas the three mixed plantations were of P. massoniana and C. hystrix, E. urophylla and E. fordii, and E. fordii and G. arborea. All eight plantations comprised evenly-aged stands, except for the E. urophylla plantation, which was a second rotation.

The study area was mostly covered by a mosaic of forest patches, and planting measures resulted in single- and mixed-species tree patches randomly distributed over the hills. Each patch typically covered 1-3 ha. The typical distances between replicate patches of the same species was $1-10 \mathrm{~km}$, whereas adjacent patches of different species were usually located $0.5-1 \mathrm{~km}$ apart. Eight to nine independent forest patches were chosen at random for each stand type. Samples for each stand type were from different patches rather than duplicate sampling within one patch. In each patch, a plot of $20 \mathrm{~m} \times 20 \mathrm{~m}$ was established at least $25 \mathrm{~m}$ away from the edge of the patch. All understory vegetation in the study area was removed twice a year. The main characteristics of the stand and sampling sites are summarized in Table 1.

\section{Soil sampling and property measurements}

In June 2014, approximately $400 \mathrm{~g}$ of soil samples were collected at depths of $0-10$ $\mathrm{cm}$ from six random locations per plot, and then mixed to form a composite soil sample in each plot. Visible roots and residues were removed prior to homogenizing the soil fraction of each sample, which was then kept on ice. Fresh soil samples were sieved through a $2-\mathrm{mm}$ mesh and stored at $-20^{\circ} \mathrm{C}$ for DNA extraction. Soil properties, including $\mathrm{pH}$, moisture, TOC, $\mathrm{TN}, \mathrm{NH}_{4}{ }^{+}-\mathrm{N}, \mathrm{NO}_{3}{ }^{-}-\mathrm{N}$, TP, AP and microbial biomass $\mathrm{C}$ were measured using methods that have been described previously (Zhang et al., 
2016).

DNA extraction and MiSeq sequencing of $16 S$ rRNA gene amplicons

Soil DNA was extracted using an MO BIO Power Soil DNA Extraction kit (MO BIO Laboratories, Carlsbad, CA, USA) according to the manufacturer's instruction. The universal primers 515F (5'-GTGCCAGCMGCCGCGGTAA-3') with 12 nt unique barcode at 5'-end and 806R (5'-GGACTACHVGGGTWTCTAAT-3') were used in PCR amplification. The detailed procedures of PCR amplification, gel extraction and MiSeq sequencing were performed as described previously (Zhang et al., 2016).

\section{Sequence analyses}

The sequence data were sorted using the QIIME Pipeline $($ ht t p: / / qi ime.org/tutorials/tutorial.htm 1 ) Methods for sequences, quality control and filtering were described in detail by Zhang et al. (2016). Re-sampling to the same sequence depth (7000 sequences per sample) for bacteria was performed using daisychopper.pl (http://www.festinalente.me/bioinf/downloads/daisychopper.pl). Samples of reads of < 7000 sequences were removed based on sample DNA sequencing results. Therefore, the number of samples of the $C$. hystrix, G. arborea single-species plantations, the $E$. fordii and $G$. arborea mixed plantation and the E. fordii and G. arborea mixed plantation was eight, whereas for the others it was nine. Operational taxonomic units (OTUs) were classified at the threshold of $97 \%$ sequence similarity. A weighted UniFrac distance metric and microbial alpha diversity based on phylotype richness were produced using the QIIME pipeline (Lozupone \& Knight, 2005).

\section{Phylogenetic distance of bacterial community measures}

To characterize phylogenetic community composition within each sample, we 
quantified mean nearest taxon distance (MNTD) and mean pairwise distance (MPD) using ses.mntd and ses.mpd in the package picante. The MNTD is the average of the shortest phylogenetic distance for each species to its closest relative in the assemblage (Webb et al., 2002; Kembel et al., 2011). It is given by:

$$
\operatorname{MNTD}=\sum \min (D \quad)
$$

where is the relative abundance of OTU $i$ in community $k, n_{k}$ is the number of OTUs in $k, \quad$ is the average of all phylogenetic distances between OTU $i$ and all other OTUs $j$ that are also in $k$ and $\min (D \quad)$ is the minimum phylogenetic distance. The MPD is the average of all phylogenetic distances connecting species together in a sample (Webb et al., 2002). It is given by:

$$
\mathrm{MPD}=\sum
$$

Phylogenetic diversity (PD) is defined as the sum of the lengths of the phylogenetic branches represented by a set of co-occurring species (Faith, 1992; Cadotte et al., 2008).

\section{Statistical analysis}

A $t$-test was used to examine the differences in phylogenetic diversity and soil variables between the single- and mixed-species plantations. Before this, the assumptions of normality and homogeneity of the variances of the residuals were tested by the Shapiro-Wilk and Levene tests. In addition, we plotted quantiles of the residuals against quantiles of a distribution (Q-Q plot) to identify any departures from a normal distribution. Among these variances, the Q-Q plot of phylogenetic diversity (PD) in single-species plantations indicated a positively skewed distribution. After transformation to square roots, the points in the Q-Q plot formed a relatively straight 
line, suggesting that the data were then close to being normally distributed. The overall structural changes of bacterial communities were evaluated by principal coordination analysis $\quad(\mathrm{PCoA}) \quad$ in $\quad$ Fast UniFrac (http://unifrac.colorado.edu/static/welcome.html). Pearson correlation analysis was applied to evaluate the correlation between diversity and stability as well as the relation between bacterial communities and environmental variables. Variation partitioning analysis (VPA) was performed to partition the relative influence of phylogenetic diversity and topological features on bacterial community stability, assuming that these factors could have different contributions on bacterial community stability. The total variance of community stability was partitioned into four components as suggested by Borcard et al. (1992) and Yang et al. (2013): (i) variation explained by phylogenetic diversity groups (MNTD, MPD and PD), (ii) variation explained by links and distance between microbial species in molecular ecological networks (MENs), (iii) variation explained by modules and connectors in MENs and (iv) unexplained variation. Similarly, VPA was also used to quantify the relative contributions of soil variables on bacterial phylogenetic diversity, presupposing that the effects of various soil factors on bacteria are different. The total variance of phylogenetic diversity was partitioned into four components: (i) variation explained by soil nitrogen content, (ii) variation explained by soil phosphorus content, (iii) variation explained by soil carbon content and (iv) unexplained variation. The $R^{2}$ values were used to calculate the variation in microbial community explained by each of the soil environmental factors. All analyses were performed in R (R Core Team, 2013).

\section{Network analysis of bacterial communities}

To understand the interactions among different species within a community, and their 
responses to environmental changes, molecular ecological networks (MENs; Deng et al., 2012) were constructed by random matrix theory (RMT)-based methods, following the molecular ecological network analyses pipeline (MENAP; http://ieg2.ou.edu/MENA). The OTUs detected in less than four of the eight or nine replicates from each stand type were removed to ensure reliable correlations. Modularity in the network could originate from specific interactions (e.g. predation or pollination), resource partitioning, ecological niche overlap, habitat heterogeneity, natural selection, convergent evolution and phylogenetic relatedness. To characterize the modularity properties, each network was separated into modules using fast greedy modularity optimization. For each network, the number of sub-modules (NM), total links (TL), positive correlation links (PCL), negative correlation links (NCL), average connectivity (AK), average path distance (GD) and modularity were calculated using the window 'global network properties' and 'module separation and modularity calculation' on the website (http://ieg2.ou.edu/MENA). The topological roles of different nodes were divided into the following four subcategories according to within-module connectivity $\left(\mathrm{Z}_{i}\right)$ and among-module connectivity $\left(P_{i}\right)$ (Zhou et al., 2011): (i) peripheral nodes were defined as nodes with $\mathrm{Z}_{i} \leq 2.5$ and $P_{i} \leq 0.62$, (ii) connectors were defined as nodes with $\mathrm{Z}_{i}>2.5$ and $P_{i} \leq 0.62$, (iii) module hubs were defined as nodes with $Z_{i}>2.5$ and $P_{i}>0.62$ and (iv) network hubs were defined as nodes with $\mathrm{Z}_{i}>2.5$ and $P_{i}>0.62$. From an ecological perspective, peripheral nodes might represent specialist connectivity within the same or similar ecological niche, whereas module hubs and connectors represent generalist links among different ecological niches, and network hubs represent super generalists, acting as both connectors and module hubs (Faust \& Raes, 2012). Cytoscape 3.0.2 software was used to visualize the network graphs (Saito et al., 2012).

This article is protected by copyright. All rights reserved. 


\section{Determination of ecosystem stability}

Stability is measured specifically by the coefficient of variation of biomass or diversity (Wang \& Loreau, 2014). A smaller coefficient of variation indicates greater ecosystem stability, which means that microbial diversity or community biomass varied less under environmental stress (Wang \& Loreau, 2016). To evaluate the effect of mixed tree species on stability of the soil microbial community, we used the coefficient of variation (CV) of microbial diversity (or microbial biomass) as indices of soil ecosystem stability. The alpha $\left(\alpha=\mathrm{CV}^{2}{ }_{\text {species }}\right)$ and beta variation $\left(\beta=\mathrm{CV}^{2}{ }_{\text {distance }}\right)$ of the bacterial community in each sample were calculated based on the method used by Wang \& Loreau (2014). In this framework, alpha variation represents local shifts in species diversity within a meta-community, which was based on richness of the OTUs, Shannon's diversity index and microbial biomass C. Beta variation represents the spatial variation in community structure, which was based on the weighted UniFrac distance of the bacterial community within each group.

\section{Results}

\section{Phylogenetic diversity of soil bacterial communities}

We found that MNTD, MPD and PD were significantly larger in the mixed plantations of P. massoniana and C. hystrix, E. urophylla and E. fordii, and E. fordii and G. arborea than in the single-species plantation of P. massoniana, C.hystrix, E. urophylla, E. fordii and G. Arborea $(P<0.001$, Figure 1, Table S1, Supporting Information). However, the variation in Chao1 richness (a non-parametric estimator that calculates the minimum number of OTUs present in a sample), Shannon's diversity index and observed species among different plantation types were not significant (Table S2, Supporting Information). 


\section{Topological features of the soil bacterial community}

In MENs, a module is a group of OTUs that have similar ecological niches or niche overlap and are well connected among themselves, but are less linked with OTUs belonging to other modules. The number of joint submodule (nodes $\geq 7$ ) nodes in the mixed plantations was larger than that in the single-species plantations. This result might indicate that soil microbial communities have more ecological niches in the mixed- than in the single-species plantations (Figure 2, Table S3, Supporting Information).

Total links, positive correlation links and average connectivity in the mixed-species plantations were less than in the single-species plantations, whereas negative interactions between two individual nodes in a community increased in response to the mixed tree species (Table S3, Supporting Information, Figure 2). Average path distances were greater in the mixed- than single-species plantations.

The number of module hubs and connectors in the mixed-species plantations was obviously larger than that in the single-species plantations (Table S3), indicating that the links between different niches or nutrient concentrations increased in response to the mixed tree species. However, the number of peripheral nodes showed no distinct change in response to the mixed tree species.

\section{Stability of the soil bacterial community}

A smaller coefficient of variation $(\mathrm{CV})$ represents greater ecosystem stability. The coefficients of variation for microbial biomass C, richness of OTUs, Shannon's diversity index, and beta diversity in the mixed plantations of $P$. massoniana and $C$. hystrix, E. urophylla and E. fordii, and E. fordii and G. arborea were markedly smaller than those in the single-species plantations of $P$. massoniana, C.hystrix, E. 
urophylla, E. fordii and G. Arborea (Figure 3). This was further supported by the results of the PCoA which showed that the distances between bacterial community structures were larger in single- than mixed-species plantations (Figure S2, Supporting Information), indicating less variation in microbial community structure in mixed species plantations.

\section{Relation between phylogenetic diversity and bacterial community stability}

Pearson correlation coefficients were used to determine the relations between phylogenetic diversity (or topological features) and bacterial community stability. The MNTD, MPD, PD, positive and negative correlation links, average connectivity and connectors were strongly related to community stability (based on the CV of beta diversity), whereas Chao1 richness, Shannon's diversity index, observed species, peripheral nodes, number of sub-modules and module hubs had only weak effects (Table S4, Supporting Information). The relations between phylogenetic diversity and stability of the bacterial community based on CV_microbial biomass C, CV_OTU richness and CV_Shannon's diversity supported this result (Table S4, Supporting Information).

The results of variance partitioning analysis (VPA) showed that a total of $69.4 \%$ of community variation could be explained by these selected variables (MNTD, MPD, PD, total links, positive and negative correlation links, average path distance, average connectivity, modules and connectors, Figure 4), indicating that they were major factors in shaping microbial community stability. Phylogenetic diversity groups (MNTD, MPD and PD) had the largest contribution (32.7\%), followed by links and distance between microbial species (total links, positive and negative correlation links, average path distance and average connectivity at $10.4 \%$ ). In contrast, modules and connectors had a smaller contribution to the variation in community stability (Figure

This article is protected by copyright. All rights reserved. 
4). This result was further confirmed by the contribution of phylogenetic diversity and topological features on bacterial community stability, represented by the $\mathrm{CV}$ of microbial biomass C, richness of OTUs and Shannon's diversity index (Figure S3, Supporting Information).

\section{Effects of soil properties on bacterial phylogenetic diversity}

Plantation type had a significant effect on soil physicochemical properties (Tables S5, S6, Supporting Information). Soil TOC, $\mathrm{TN}, \mathrm{NO}_{3}{ }^{-} \mathrm{N}$ and $\mathrm{TP}$ contents were larger in mixed- than single-species plantations (Table S6, Supporting Information). Soil $\mathrm{NH}_{4}{ }^{+}-\mathrm{N}$ and AP concentrations showed similar trends in response to mixed tree species, except that they were larger in the E. fordii single-species plantation than in the E. urophylla and E. fordii mixed plantation. The soil $\mathrm{C} / \mathrm{N}$ ratio was significantly smaller in the mixed- than single-species plantations, but the $\mathrm{C} / \mathrm{N}$ ratio was larger in the E. urophylla and E. fordii mixed plantation than the E. fordii single-species plantation. Soil $\mathrm{pH}$ and moisture did not vary significantly between single- and mixed-species plantations (Table S6, Supporting Information).

Pearson's correlation coefficients between soil variables and phylogenetic diversity showed that the observed variation in bacterial phylogenetic diversity was moderately but significantly correlated with soil variables, except for $\mathrm{pH}$ and moisture $(r<0.14, P<0.01$, Table 2). There was a negative correlation between soil $\mathrm{C} / \mathrm{N}$ ratio and phylogenetic diversity, whereas other soil variables, such as soil TOC, $\mathrm{NO}_{3}{ }^{-} \mathrm{N}$ and AP, were positively correlated (Table 2). The VPA analysis was performed to quantify the relative contributions of soil variables to the changes in phylogenetic diversity. Soil TN, $\mathrm{NH}_{4}{ }^{+}-\mathrm{N}$ and $\mathrm{NO}_{3}{ }^{-}-\mathrm{N}$ explained $22.7 \%$ of the variation, soil organic $\mathrm{C}$ and the $\mathrm{C} / \mathrm{N}$ ratio explained $13.6 \%$, and soil $\mathrm{TP}$ and $\mathrm{AP}$ explained $11.7 \%$ of the variation, leaving $31.6 \%$ of the variation unexplained (Figure S4, Supporting 
Information).

\section{Discussion}

Plantations of mixed tree species improved bacterial phylogenetic diversity

Phylogenetic distance can be used to represent similarities, differences and ecological niches of species (Webb et al., 2002; Cadotte et al., 2008). Our results showed that mixed tree species increased MNTD, MPD and PD of soil bacterial communities more than single-species plantations (Figure 1, Table S1). In addition, MENs demonstrated that there were more sub-modules (one sub-module represents one ecological niche) in mixed- than single-species plantations (Figure 2, Table S3). All these results suggest that there were more ecological niches in the mixed- than single-species plantations. This was not a surprise, considering that bacterial taxa, especially the prevailing unicellular bacteria, inhabit soil niches at a very small scale that often have close connections to soil properties (Vos et al., 2013). Evidence suggests that multi-species plantations might mitigate reduction in site productivity and, in some cases, can even improve the quality of soil resources (Montagnini, 2000). In this study, plant nutrient contents were greater in mixed plantations (Table S6), and more importantly, the observed increases in bacterial phylogenetic diversity were explained by changes in soil properties, such as $\mathrm{NO}_{3}{ }^{-}-\mathrm{N}$ and $\mathrm{NH}_{4}{ }^{+}-\mathrm{N}$. Soil $\mathrm{pH}$ has been identified as the most important factor affecting soil bacterial communities (Ferrenberg et al., 2013). However, we did not find a significant effect of pH on bacterial communities, because it was similar across the different plantations. Thus, our study suggests that mixed-species plantations increased bacterial phylogenetic diversity by improving soil conditions and supplying more heterogeneous resources for soil microorganisms.

This article is protected by copyright. All rights reserved. 
There were no significant differences in species richness between single- and mixed-species plantations in spite of more niches occurring in the mixed-species plantations. There was only one condition under which there were more niche overlaps in a single-species plantation. Indeed, there were more niche overlaps in single- than mixed-species plantations in this study (Figure 2, Table S3). An increase in the number of niche overlaps might result in an increase in positive relations between species (Faust \& Raes, 2012). If this is correct, the number of positive correlations should be larger in the single- than mixed-species plantations, which we observed in this study. Therefore, our findings suggest that mixed tree species might affect phylogenetic diversity and interactions between species, but not species richness.

\section{Phylogenetic diversity-stability relations and underlying mechanisms}

Microbial ecologists face challenges in evaluating stability of the soil microbial community because of complexity and variability of the soil. Alpha and beta variation are used to reflect ecosystem stability at spatial scales in a meta-community (Wang \& Loreau, 2016). Smaller values of alpha or beta variation represent greater ecosystem stability, which means that microbial diversity or community structure has less variation under environmental stress (Wang \& Loreau, 2014). Our data showed that the coefficients of variation of biomass, alpha and beta variation of bacterial communities were smaller in mixed- than single-species plantations (Figure 3), suggesting that mixed tree species enhanced stability of the soil microbial community. In accord with this, previous studies have suggested that mixed tree species could improve stability of the soil microbial community through greater microbial diversity and more resistant taxa because of increased resource availability (Royer-Tardif et al., 2010)

This article is protected by copyright. All rights reserved. 
Diversity, however, is not always directly responsible for stability. Pfisterer \& Schmid (2002) found an inverse relation between plant species richness resistance to drought. Similarly, Griffiths et al. ( 2001) found that increasing the number of grassland plant species from one to six did not alter soil functional stability. Studies have shown that a positive diversity-stability correlation is not a pure diversity effect, and have indicated that ecosystem function and stability are more directly related to functional diversity (Cadotte et al., 2012; Blüthgen et al., 2016). In this study, we have shown that phylogenetic diversity (i.e. niche differentiation) is better at explaining the variation in ecosystem stability than species richness (Figure 4, Table S4).

There are two underlying mechanisms to explain why greater phylogenetic diversity in communities would result in increased stability of the bacterial community. First, large phylogenetic distances in soil bacterial communities reflect communities with more differentiation between ecological niches and a greater potential to use resources in complementary ways (e.g. partitioning of soil resources; Cadotte et al., 2012; Zuppinger-Dingley et al., 2014). In this study, soil microbial communities with large phylogenetic diversity shared more ecological niches and were more stable in mixed plantations (Figures 2 and 3, Table S3). It is possible that species in a microbial community with more differentiation of ecological niches protect communities (or ecosystems) from decline, because some species will maintain community stability even if others fail (Yachi \& Loreau, 1999). Second, microbial communities with short phylogenetic distances among individuals could lead to large connectivity among species, resulting in the community shifting as a whole against environmental changes and then decreasing the stability of the microbial community (May, 1972). Our results revealed that microbial assemblages 
with large phylogenetic diversity in the mixed plantations were associated with smaller average connectivity and clustering coefficients, and showed more stability than communities with the strong connectivity in single-species plantations (Figure 4, Tables S3 and S4). We also found that the mixed plantations had more connectors and module hubs (Table S3), which represent links among different ecological niches and trophic levels from an ecological perspective (Faust \& Raes, 2012). Therefore, bacterial communities with more connectors and module hubs in mixed plantations exhibit more potential to use resources in complementary ways, and thus improve the stability of the microbial community.

\section{Conclusions}

Phylogenetic diversity determines phylogenetic distances and interactions among species within a community, which is useful for estimating the effects of biodiversity on ecosystem functions. Our results suggested that mixed tree species had a positive effect on stability of the bacterial community, which could be achieved through greater phylogenetic diversity. This is probably because species in a microbial community with long phylogenetic distances result in weak interactions between individual species, which serves to protect the community from a decline in stability. Even if some species fail against environmental fluctuations, others might not necessarily change (i.e. the insurance hypothesis). We verified this further by showing that microbial communities with large phylogenetic diversity in mixed-species plantations had weak interactions, whereas those with small phylogenetic diversity in single-species plantations had stronger interactions. Our study suggested that microbial phylogenic diversity and interactions between individual species could complement surveys on diversity when evaluating the potential effects of changes in vegetation on microbial communities.

This article is protected by copyright. All rights reserved. 


\section{Supporting Information}

The following supporting information is available in the online version of this article:

Table S1 Results from $t$-tests for the difference in phylogenetic diversity between the single- and mixed-species plantations.

Table S2 Means and levels of significance of alpha diversity for the bacterial community in the single- and mixed-species plantations.

Table S3 Topological properties of the empirical MENs of soil prokaryotic communities under single- and mixed-species plantations

Table S4 Pearson correlations between soil bacterial diversity (or interaction) and stability.

Table S5 Soil properties at single- and mixed-species plantations.

Table S6 Summary results from $t$-tests for the soil variables between the single- and mixed-species plantations.

Figure S1 Plant and soil development processes at the study site.

Figure S2 Principal coordinate analysis (PCoA) of weighted UniFrac distances of bacterial communities for single- and mixed-species plantations.

Figure S3 Variation partitioning analysis to partition relative influence of phylogenetic structure and topological features on the stability of the bacterial community.

Figure S4 Variation partitioning analysis to partition relative influence of soil variables on soil bacterial phylogenetic diversity.

\section{Acknowledgements}

We thank the Guangxi Nong gang National Nature Reserve management for assisting with research permits; Chi Liu and Qian Liu for their assistance in field sampling and 
data analysis. We also thank Alison Beamish at the University of British Columbia for her assistance with English language and grammatical editing of the manuscript. We gratefully acknowledge support from the Chinese Academy of Forestry's Experimental Center of Tropical Forestry. We also thank the Ministry of Science and Technology (2015DFA31440), Natural Science Foundation of China (31700383, 31290223) and Special Research Program for Public-welfare Forestry (No 201404201) for financial support of this research.

\section{References}

Barberán, A., McGuire, K.L., Wolf, J.A., Jones, F.A., Wright, S.J., Turner, B.L. et al. 2015. Relating belowground microbial composition to the taxonomic, phylogenetic, and functional trait distributions of trees in a tropical forest. Ecology Letters, 18, $1397-1405$.

Blüthgen, N., Simons, N.K., Jung, K., Prati, D., Renner, S.C., Boch, S. et al. 2016. Land use imperils plant and animal community stability through changes in asynchrony rather than diversity. Nature Communications, 7, 10697.

Borcard, D., Legendre, P. \& Drapeau, P. 1992. Partialling out the spatial component of ecological variation. Ecology, 73, 1045-1055.

Cadotte, M.W., Cardinale, B.J. \& Oakley, T.H. 2008. Evolutionary history and the effect of biodiversity on plant productivity. Proceedings of the National Academy of Sciences of the United States of America, 105, 17012-17017.

Cadotte, M.W., Dinnage, R. \& Tilman, D. 2012. Phylogenetic diversity promotes ecosystem stability. Ecology, 93, S223-S233.

Cardinale, B.J., Duffy, J.E., Gonzalez, A., Hooper, D.U., Perrings, C., Venail, P. et al. 2012. Biodiversity loss and its impact on humanity. Nature, 486, 59-67.

This article is protected by copyright. All rights reserved. 
Deng, Y., Jiang, Y.H., Yang, Y., He, Z., Luo, F. \& Zhou, J. 2012. Molecular ecological network analyses. BMC Bioinformatics, 13, 113-133.

Faith, D.P. 1992. Conservation evaluation and phylogenetic diversity. Biological Conservation, 61, 1-10.

Faust, K. \& Raes, J. 2012. Microbial interactions: from networks to models. Nature Reviews Microbiology, 10, 538-550.

Ferrenberg, S., O'Neill, S.P., Knelman, J.E., Todd, B., Duggan, S., Bradley, D. et al. 2013. Changes in assembly processes in soil bacterial communities following a wildfire disturbance. The ISME Journal, 7, 1102-1111.

Griffiths, B., Bonkowski, M., Roy, J. \& Ritz, K. 2001. Functional stability, substrate utilisation and biological indicators of soils following environmental impacts. Applied Soil Ecology, 16, 49-61.

Griffiths, B.S. \& Philippot, L. 2013. Insights into the resistance and resilience of the soil microbial community. FEMS Microbiology Reviews, 37, 112-129.

Huang, X., Liu, S., Wang, H., Hu, Z., Li, Z. \& You, Y. 2014. Changes of soil microbial biomass carbon and community composition through mixing nitrogen-fixing species with Eucalyptus urophylla in subtropical China. Soil Biology \& Biochemistry, 73, 42-48.

Jiang, L. 2007. Negative selection effects suppress relationships between bacterial diversity and ecosystem functioning. Ecology, 88, 1075-1085.

Kang, B., Liu, S., Shi, Z., Wen, Y., Cai, D., Lu, L. et al. 2005. Understory vegetation composition and main woody population niche of artificial masson pine forest in south subtropical area. Chinese Journal of Applied Ecology, 25, 2173-2179.

Kelty, M.J. 2006. The role of species mixtures in plantation forestry. Forest Ecology and Management, 233, 195-204.

This article is protected by copyright. All rights reserved. 
Kembel, S.W., Eisen, J.A., Pollard, K.S. \& Green, J.L. 2011. The phylogenetic diversity of metagenomes. PLoS One, 6, e23214.

Lozupone, C. \& Knight, R. 2005. UniFrac: a new phylogenetic method for comparing microbial communities. Applied and Environmental Microbiology, 71, 8228-8235.

May, R. M. 1972. Will a large complex system be stable? Nature, 238, 413-414.

McCann, K.S. 2000. The diversity-stability debate. Nature, 405, 228-233.

Montagnini, F. 2000. Accumulation in above-ground biomass and soil storage of mineral nutrients in pure and mixed plantations in a humid tropical lowland. Forest Ecology and Management, 134, 257-270.

Pan, Y., Birdsey, R.A., Fang, J., Houghton, R., Kauppi, P.E., Kurz, W.A. et al. 2011. A large and persistent carbon sink in the world's forests. Science, 333, 988-993.

Pfisterer, A.B. \& Schmid, B. 2002. Diversity-dependent production can decrease the stability of ecosystem functioning. Nature, 416, 84-86.

Prescott, C.E. \& Grayston, S.J. 2013. Tree species influence on microbial communities in litter and soil: current knowledge and research needs. Forest Ecology and Management, 309, 19-27.

Roger, F., Bertilsson, S., Langenheder, S., Osman, O.A. \& Gamfeldt, L. 2016. Effects of multiple dimensions of bacterial diversity on functioning, stability and multifunctionality. Ecology, 97, 2716-2728.

Rousk J, Bååth E, Brookes P.C., Lauber, C. L., Lozupone, C., Caporaso, J. G. et al. 2010. Soil bacterial and fungal communities across a pH gradient in an arable soil. The ISME Journal, 4, 1340-1351.

Royer-Tardif, S., Bradley, R.L. \& Parsons, W.F.J. 2010. Evidence that plant diversity and site productivity confer stability to forest floor microbial biomass. Soil Biology \& Biochemistry, 42, 813-821.

This article is protected by copyright. All rights reserved. 
Saito, R., Smoot, M.E., Ono, K., Ruscheinski, J., Wang, P.L., Lotia, S. et al. 2012. A travel guide to Cytoscape plugins. Nature Methods, 9, 1069-1076.

Sicardi, M., García-Préchac, F. \& Frioni, L. 2004. Soil microbial indicators sensitive to land use conversion from pastures to commercial Eucalyptus grandis (Hill ex Maiden) plantations in Uruguay. Applied Soil Ecology, 27, 125-133.

Team, C.R. 2013. R: A Language and environment for statistical computing. Computing, 14, 12-21.

Vos, M., Wolf, A.B., Jennings, S.J. \& Kowalchuk, G.A. 2013. Micro-scale determinants of bacterial diversity in soil. FEMS Microbiology Reviews, 37, 936954.

Wang, S. \& Loreau, M. 2014. Ecosystem stability in space: $\alpha, \beta$ and $\gamma$ variability. Ecology Letters, 17, 891-901.

Wang, S. \& Loreau, M. 2016. Biodiversity and ecosystem stability across scales in metacommunities. Ecology Letters, 19, 510-518.

Webb, C.O., Ackerly, D.D., McPeek, M.A. \& Donoghue, M.J. 2002. Phylogenies and community ecology. Annual Review of Ecology and Systematics, 33, 475-505.

Wertz, S., Degrange, V., Prosser, J.I., Poly, F., Commeaux, C., Guillaumaud, N. \& Le Roux, X. 2007. Decline of soil microbial diversity does not influence the resistance and resilience of key soil microbial functional groups following a model disturbance. Environmental Microbiology, 9, 2211-2219.

Yachi, S. \& Loreau, M. 1999. Biodiversity and ecosystem productivity in a fluctuating environment: the insurance hypothesis. Proceedings of the National Academy of Sciences of the United States of America, 96, 1463-1468.

Yang, Y., Wu, L., Lin, Q., Yuan, M., Xu, D., Yu. H., et al. 2013. Responses of the functional structure of soil microbial community to livestock grazing in the $\mathrm{T}$

This article is protected by copyright. All rights reserved. 
ibetan alpine grassland. Global Change Biology, 19, 637-648.

Zhang, X., Liu, S., Li, X., Wang, J., Ding, Q., Wang, H. et al. 2016. Changes of soil prokaryotic communities after clear cutting in a karst forest: evidences for cutting-based disturbance promoting deterministic processes. FEMS Microbiology Ecology, 92, fiw026.

Zhou, J., Deng, Y., Luo, F., He, Z. \& Yang, Y. 2011. Phylogenetic molecular ecological network of soil microbial communities in response to elevated $\mathrm{CO}_{2}$. mBio, 2, e00122-11.

Zuppinger-Dingley, D., Schmid, B., Petermann, J.S., Yadav, V., De Deyn, G.B. \& Flynn, D.F. 2014. Selection for niche differentiation in plant communities increases biodiversity effects. Nature, 515, 108-111.

\section{Tables}

Table 1 Characteristics of the single- and mixed-species plantations (mean and standard error)

\begin{tabular}{|c|c|c|c|c|c|c|c|c|}
\hline Plantation type & PM & $\mathrm{CH}$ & ES & $\mathrm{EF}$ & GA & MPC & MEE & MGE \\
\hline Stem density /tree $\mathrm{hm}^{2}$ & $\begin{array}{r}404.4 \pm \\
6.5\end{array}$ & $\begin{array}{r}415.7 \pm \\
6.4 \\
\end{array}$ & $\begin{array}{r}558.1 \pm \\
8.3 \\
\end{array}$ & $\begin{array}{r}410.3 \pm \\
5.7\end{array}$ & $\begin{array}{r}379.6 \pm \\
4.5\end{array}$ & $\begin{array}{r}400.6 \pm \\
4.5\end{array}$ & $\begin{array}{r}567.5 \pm \\
9.8\end{array}$ & $\begin{array}{r}466.9 \pm \\
8.6 \\
\end{array}$ \\
\hline $\begin{array}{l}\text { Mean of diameter at breast } \\
/ \mathrm{cm}\end{array}$ & $25.7 \pm 1.3$ & $\begin{array}{r}26.3 \pm \\
0.5 \\
\end{array}$ & $19.4 \pm 0.7$ & $20.3 \pm 1.1$ & $26.7 \pm 0.8$ & $28.4 \pm 0.9$ & $12.5 \pm 1.2$ & $\begin{array}{r}23.4 \pm \\
0.7 \\
\end{array}$ \\
\hline Mean height $/ \mathrm{m}$ & $18.4 \pm 2.1$ & $18.3 \pm 2.5$ & $21.5 \pm 1.5$ & $17.5 \pm 1.9$ & $18.6 \pm 2.4$ & $19.3 \pm 2.1$ & $18.4 \pm 1.6$ & $\begin{array}{r}20.5 \pm \\
0.9 \\
\end{array}$ \\
\hline Slope degree $/^{\circ}$ & $35.3 \pm 3.9$ & $32.4 \pm 4.4$ & $28.4 \pm 3.7$ & $29.4 \pm 1.5$ & $24.3 \pm 5.3$ & $29.7 \pm 6.2$ & $31.4 \pm 7.3$ & $\begin{array}{r}26.4 \pm \\
4.9\end{array}$ \\
\hline Elevation $/ \mathrm{m}$ & $\begin{array}{r}545.3 \pm \\
4.3 \\
\end{array}$ & $\begin{array}{r}562.8 \pm \\
7.2 \\
\end{array}$ & $\begin{array}{r}147.5 \pm \\
6.5 \\
\end{array}$ & $\begin{array}{r}345.4 \pm \\
7.3 \\
\end{array}$ & $\begin{array}{r}213.4 \pm \\
8.8 \\
\end{array}$ & $\begin{array}{r}176.3 \pm \\
6.7 \\
\end{array}$ & $\begin{array}{r}234.2 \pm \\
9.3 \\
\end{array}$ & $\begin{array}{r}373.8 \pm \\
5.5 \\
\end{array}$ \\
\hline
\end{tabular}

PM, Pinus massoniana; CH, Castanopsis hystrix; ES, Second-rotation plantation of Eucalyptus urophylla; EF, Erythrophleum fordii; GA, Gmelina arborea; MPC, mixed plantation of P. massoniana and C. hystrix; MEE, mixed plantation of E. urophylla and E. fordii; MEG, mixed plantation of E. fordii and G. arborea.

This article is protected by copyright. All rights reserved. 
Table 2 Pearson's correlation coefficients between soil environmental variables and phylogenetic diversity

\begin{tabular}{|c|c|c|c|c|c|c|c|c|c|c|}
\hline & $\begin{array}{l}\text { Correlation } \\
\text { coefficient }\end{array}$ & $\begin{array}{l}\mathrm{TOC} \\
\mathrm{g} \mathrm{kg}^{-1}\end{array}$ & $\begin{array}{l}\mathrm{TN} / \\
\mathrm{g} \mathrm{kg}^{-1}\end{array}$ & $\begin{array}{l}\mathrm{C} / \mathrm{N} / \\
\%\end{array}$ & $\begin{array}{l}\mathrm{NH}_{4}{ }^{+}-\mathrm{N} / \\
\mathrm{mg} \mathrm{kg}^{-1}\end{array}$ & $\begin{array}{l}\mathrm{NO}_{3}^{-}-\mathrm{N} / \\
\mathrm{mg} \mathrm{kg}^{-1}\end{array}$ & $\begin{array}{l}\mathrm{AP} / \\
\mathrm{mg} \mathrm{kg}\end{array}$ & $\begin{array}{l}\mathrm{TP} / \\
\mathrm{g} \mathrm{kg}^{-1}\end{array}$ & $\begin{array}{l}\text { Soil } \\
\text { pH }\end{array}$ & $\begin{array}{l}\text { SM / } \\
\%\end{array}$ \\
\hline \multirow[t]{2}{*}{ MNTD } & $r$ & 0.36 & 0.48 & -0.34 & 0.68 & 0.39 & 0.31 & 0.25 & 0.14 & -0.04 \\
\hline & $P$ & $<0.001$ & $<0.001$ & $<0.001$ & $<0.001$ & 0.001 & 0.01 & 0.04 & 0.24 & 0.74 \\
\hline \multirow[t]{2}{*}{ MPD } & $r$ & 0.45 & 0.21 & -0.44 & 0.42 & 0.79 & 0.22 & 0.57 & 0.12 & 0.12 \\
\hline & $P$ & $<0.001$ & 0.06 & $<0.001$ & 0.001 & $<0.001$ & $<0.001$ & 0.001 & 0.33 & 0.32 \\
\hline \multirow[t]{2}{*}{ PD } & $r$ & 0.38 & 0.37 & -0.36 & 0.30 & 0.64 & 0.12 & 0.55 & 0.02 & 0.04 \\
\hline & $P$ & $<0.001$ & $<0.001$ & 0.01 & 0.02 & $<0.001$ & 0.33 & $<0.001$ & 0.86 & 0.75 \\
\hline
\end{tabular}

MNTD, mean nearest taxon distance; MPD, mean pairwise distance; PD, Phylogenetic diversity; TOC, total organic carbon; $\mathrm{TN}$, total nitrogen; $\mathrm{C} / \mathrm{N}$, soil carbon/ nitrogen ratio; $\mathrm{NH}_{4}{ }^{+}-\mathrm{N}$, ammonium nitrogen; $\mathrm{NO}_{3}{ }^{-} \mathrm{N}$, nitrate nitrogen; TP, soil total phosphorus; AP, available phosphorus; Soil $\mathrm{pH}$, soil $\mathrm{pH}$ value; SM, soil moisture.

\section{Figures}

Figure 1 Mean nearest taxon distance (MNTD), mean pairwise distance (MPD) and phylogenetic diversity (PD) of bacterial communities in single- and mixed-species plantations. PM, P. massoniana; CH, Castanopsis hystrix; ES, Second-rotation plantation of Eucalyptus urophylla; EF, Erythrophleum fordii; GA, Gmelina arborea; MPC, mixed plantation of P. massoniana and C. hystrix; MEE, mixed plantation of $E$. urophylla and E. fordii; MEG, mixed plantation of E. fordii and G. arborea.
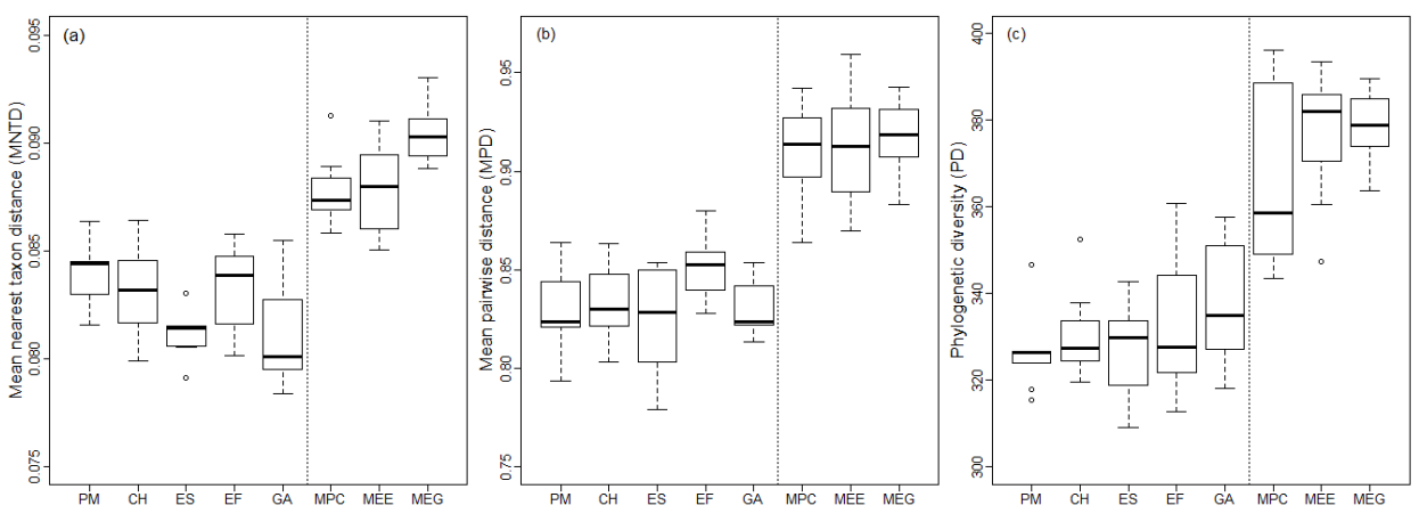

Figure 2 The molecular ecological networks (MENs) of bacterial communities in single- and mixed-species plantations. Molecular ecological networks (MENs)

This article is protected by copyright. All rights reserved. 
represents various biological interactions in an ecosystem in which different nodes (OTUs) are linked by edges (interactions). Number in the circles is the module number. Red line means positive correlation, and grey line means negative correlation.

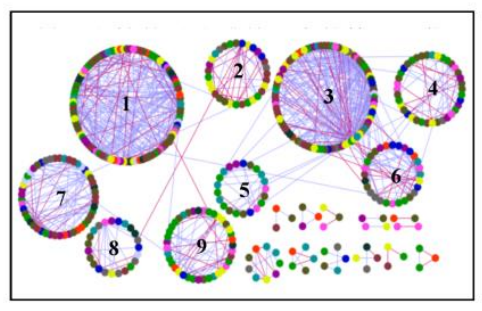

Pure plantation of PM

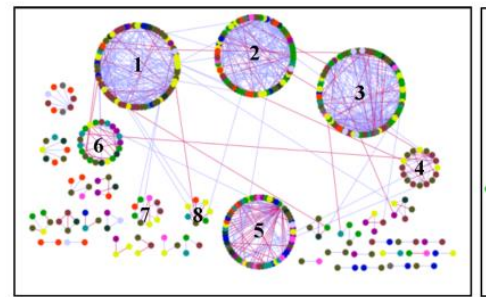

Pure plantation of ES

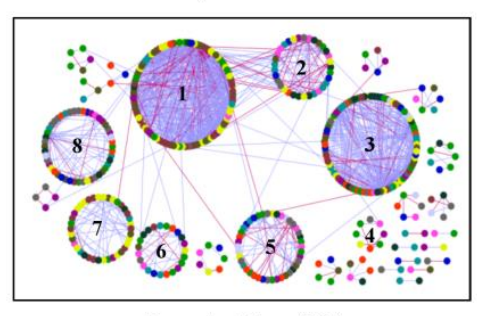

Pure plantation of GA

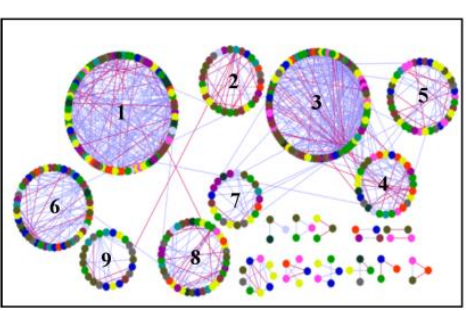

Pure plantation of $\mathrm{CH}$

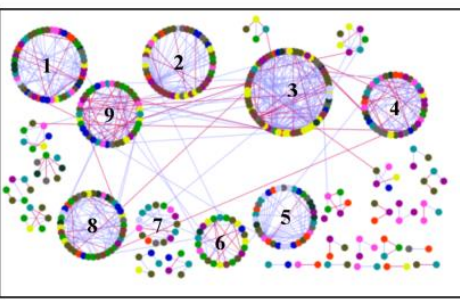

Pure plantation of EF

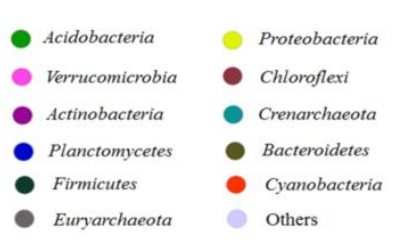

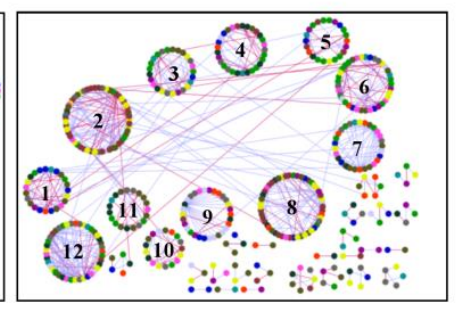

Mixed plantation of PM and $\mathrm{CH}$

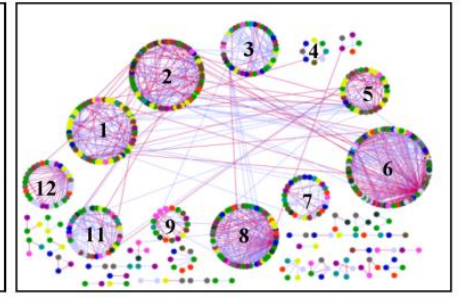

Mixed plantation of ES and EF

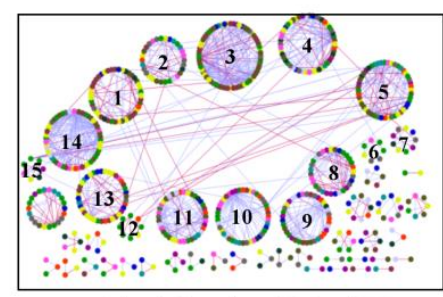

Mixed plantation of GA and EF

Figure 3 The coefficient of variation $(\mathrm{CV})$ of microbial biomass $\mathrm{C}$, richness of OTUs, Shannon's diversity index and beta diversity under single- and mixed-species plantations. The large variable coefficients indicate less stability in a microbial system.

This article is protected by copyright. All rights reserved. 

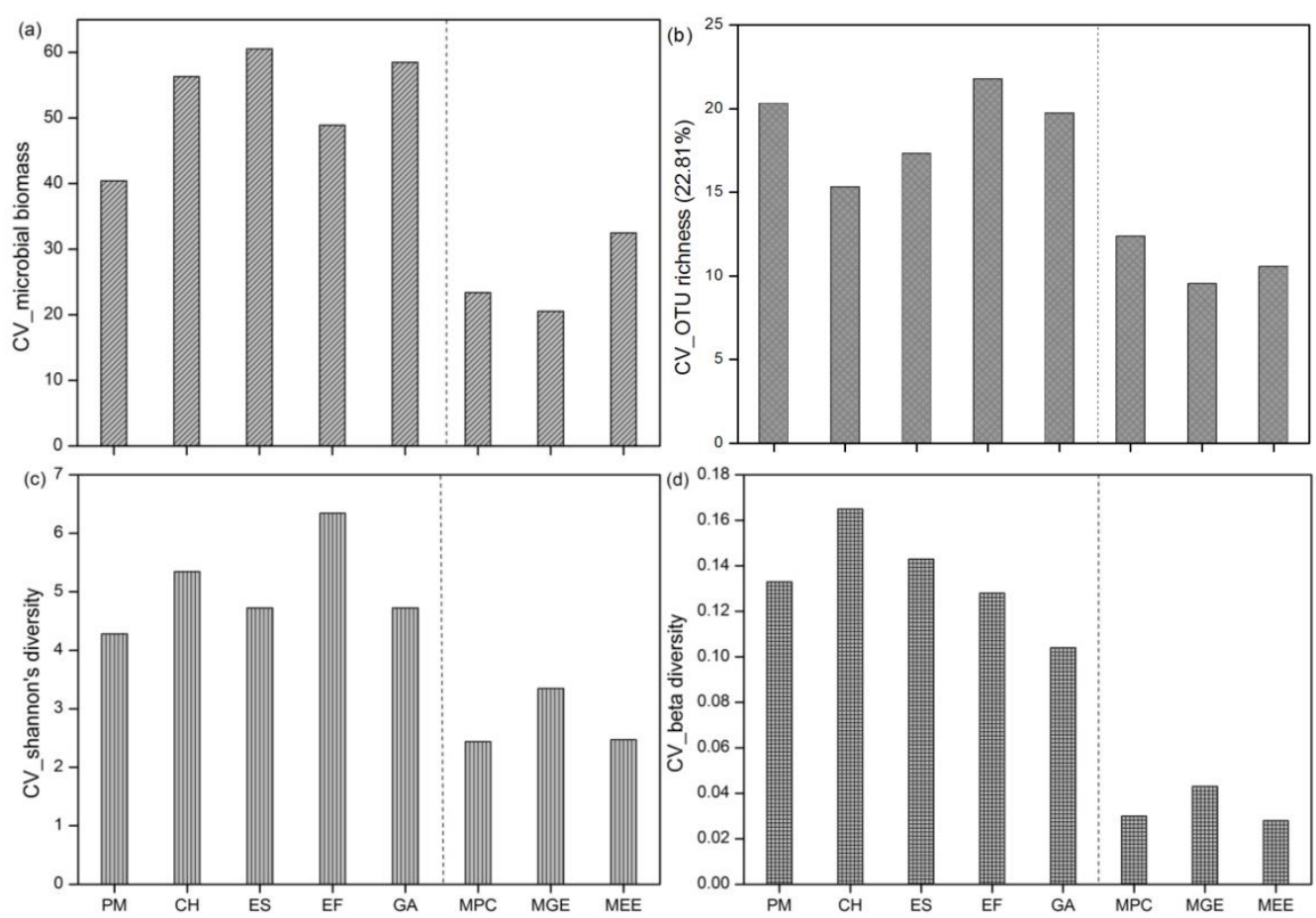

Figure 4 Variation partitioning analysis partitions the relative influence of phylogenetic structure and topological features on prokaryotic community stability. The variables are divided into phylogenetic structure groups (MNTD, MPD and PD), links and distance between microbial species (total, positive and negative correlation links, and average connectivity and average path distance) and modules and connectors in MENs (number of sub-modules, connectors and module hubs). The circles represent individual groups of variables by partitioning the effects of other groups. The geometric areas of the circles are proportional to the percentage? respective effect as indicated by the numbers. The rectangles between the circles represent the joint effect of the circles on both sides of them. The portion unexplained by any of the tested variable groups is shown in the rectangle at the bottom of the figure.

This article is protected by copyright. All rights reserved. 
